\title{
Unsuitable readability levels of patient information pertaining to dementia and related diseases: a comparative analysis
}

\author{
Markus Weih, Angelika Reinhold, \\ Tanja Richter-Schmidinger, Anne-Kathrin Sulimma, \\ Harald Klein ${ }^{2}$ and Johannes Kornhuber \\ ${ }^{1}$ Department of Psychiatry and Psychotherapy, University Erlangen-Nuremberg, Erlangen, Germany \\ ${ }^{2}$ Department of Social Sciences, University of Osnabrück, Germany
}

Background: Our study investigated the readability of printed material about dementia that is offered to patients and caregivers.

Methods: Comparisons of various brochures (at least three standard pages in length) on dementia and related disorders were made using automated measuring by the SMOG readability index grade.

Results: 118 brochures were assessed (25 in English, 93 in German), for which the mean readability was found to be high school/college level as measured by the SMOG readability index (grade $13.6 \pm 1.8$ ). No differences in readability were observed between materials produced by pharmaceutical companies and other sources. Furthermore, recently published brochures were not more readable than older ones. Shorter brochures, English brochures and those containing medical facts were easier to read than longer ones, those written in German or brochures primarily addressing psychosocial care/social issues. The sentence length was above the 20 word recommendation in $25 \%$ of the brochures. The average font size of the brochure texts was small (mean font size $11.1 \pm 1.6$ point) with only $25 \%$ of brochures having a font size of 12 or more, as recommended.

Conclusions: Written patient information and educational material of more than three standard pages is often published at unsuitably high readability levels using small fonts. Information material about dementia should be designed and tested prior to distribution among patients and caregivers. Future studies should address material shorter than three pages and material for younger caregivers.

Key words: Alzheimer's disease, psycho education, patient communication

Correspondence should be addressed to: Professor Markus Weih, Department of Psychiatry and Psychotherapy, University Erlangen-Nuremberg, Schwabachanlage 6, 91054 Erlangen, Germany. Phone: +49 9131 854-4698; Fax.: +49 9131 854-4196. Email: markus.weih@uk-erlangen.de. Received 28 Feb 2008; revision requested 18 Apr 2008; revised version received 29 Apr 2008; accepted 30 Apr 2008. First published online 30 June 2008. 


\section{Introduction}

Besides age, a low level of education is an important socio-epidemiologic risk factor for dementia in later life. Early recognition of the signs and symptoms of dementia and adherence to medical treatments offered are vital. It is therefore crucial that the information given to patients and their caregivers is clear and readily accessible. Such information should promote shared decision-making by helping those involved understand the course of the disease, as well as understand the risks and benefits of anti-dementia and psychosocial treatments. Older people, patients and their often younger caregivers usually receive initial information in written form, predominantly via leaflets, information brochures and/or the internet. Written information, freely available, is cost-efficient and is often used by healthcare professionals in order to complement verbal information. The available material, however, is usually written by members of the health system who differ from the target group with respect to age and education. It is therefore not surprising that much of the printed information given to the target group requires high reading skills.

Despite efforts to improve education in the industrialized world, a considerable proportion of the population has reading difficulties or a level of literacy that does not exceed 6th-8th school grade (Davis et al., 1990; Weiss et al., 1994; Hearth-Holmes et al., 1997; Galloway et al., 2003).

Written medical information pertaining to symptoms, prognosis and treatment is often complex and difficult for patients with cognitive impairment and for caregivers to understand. Unfortunately, older people with cognitive decline or mild dementia as well as their caregivers are likely to have a low level of education and reduced literacy skills, which consequently reduces their ability to understand medical procedures and available treatments.

Readability is a construct that has been investigated in the social sciences for several decades. It has been shown that several factors influence readability, including font type and size, word length and sentence length. Readability indexes have been developed in order to measure and compare texts, as well as to relate them to external parameters such as school grade or neuropsychological test results. The SMOG (Simple Measure of Gobbledygook) index, derived from Gunning's Fog Index (Gunning, 1952), estimates the number of years of education required in order for a patient/person to understand a text passage. It is based on counting polysyllabic words and has been widely used in medicine (McLaughlin, 1969). Today, the SMOG index can be calculated using software such as Text Quest (Klein, 2004) or internet-based tools (National Literacy Trust, 2008). Other readability indexes, for example the "Flesch-Kincaid Grade Level formula" (Flesch, 1948), are offered as extra modules in commonly available commercial word processors (e.g. Microsoft Word).

Information deficits on the patient's side may have an enormous impact on their health. Previous studies have shown that poor legibility of drug labels leads to non-compliance, poor health (Weiss et al., 1991) and increased health costs (Weiss and Palmer, 2004). Earlier studies have also shown that the reading ability of patients is lower than expected and that the reading level of written patient 
Table 1. Patient reading ability and level of written material

\begin{tabular}{|c|c|c|c|}
\hline A U T H OR & $\begin{array}{l}\text { MATERIAL } \\
\text { TOPIC OR } \\
\text { SUBJECTS }\end{array}$ & $\begin{array}{l}\text { READING } \\
\text { LEVEL OF } \\
\text { PATIENTS }\end{array}$ & $\begin{array}{l}\text { READING LEVEL } \\
\text { OF MATERIAL }\end{array}$ \\
\hline Powers, 1988 & $\begin{array}{l}\text { Emergency } \\
\text { medicine }\end{array}$ & $40 \%<8^{\text {th }}$ grade & $11^{\text {th }}$ grade \\
\hline Davis et al., 1990 & Ambulatory care & Mean $6.5^{\text {th }}$ grade & $11^{\text {th }}-14^{\text {th }}$ grade \\
\hline Davis et al., 1994 & Pediatric patients & $7^{\text {th }}-8^{\text {th }}$ grade & $80 \% \geq 10^{\text {th }}$ grade \\
\hline $\begin{array}{l}\text { Hearth-Holmes } \\
\text { et al., } 1997\end{array}$ & $\begin{array}{l}\text { Lupus } \\
\text { erythematosus }\end{array}$ & Mean $7^{\text {th }}-8^{\text {th }}$ grade & $89 \% \geq 9^{\text {th }}$ grade \\
\hline $\begin{array}{l}\text { Mader and Playe, } \\
1997\end{array}$ & $\begin{array}{l}\text { Emergency } \\
\text { medicine }\end{array}$ & & Average $10^{\text {th }}$ grade \\
\hline Smith et al., 1998 & Asthma information & & $\begin{array}{l}\text { Mean SMOG } \\
\quad(\text { McLaughlin, 1969) } 8.7\end{array}$ \\
\hline Chesson et al., 1998 & Sleep disorders & & $94 \% \geq 12^{\text {th }}$ grade \\
\hline Estrada et al., 2000 & Oral anticoagulation & & $\begin{array}{l}\text { Mean SMOG } 10.7 ; 100 \% \\
\geq 7^{\text {th }} \text { grade }\end{array}$ \\
\hline Kubba, 2000 & $\begin{array}{l}\text { Otolaryngology } \\
\text { outpatients }\end{array}$ & $28 \% \leq 8^{\text {th }}$ grade & Median $11^{\text {th }}$ grade \\
\hline Galloway et al., 2003 & $\begin{array}{l}\text { Electro diagnostic } \\
\text { medicine }\end{array}$ & $7^{\text {th }}-8^{\text {th }}$ grade & Mean $10.5^{\text {th }}$ grade \\
\hline $\begin{array}{l}\text { Paasche-Orlow et al., } \\
2003\end{array}$ & $\begin{array}{l}\text { IRB Informed } \\
\text { Consent Forms }\end{array}$ & & Mean $10.6^{\text {th }}$ grade \\
\hline
\end{tabular}

information pertaining to medical procedures exceeds the actual reading ability of the targeted group by several school grade years (Table 1).

The research question of the present study was whether the readability levels of freely available brochures about dementia and related disorders matches the assumed reading skills of the targeted population (patients and their caregivers).

\section{Methods}

We searched the internet, focus group publications, government and nongovernment organizations and pharmaceutical companies for printed patient information on dementia and cognitive decline using the following keywords (and/or): Alzheimer's disease, disease and associated health problems, cognitive/ memory impairment; dementia.

Predefined inclusion criteria were:

- that the information be freely available (printed brochure or pdfformat)

- that the information be targeted at the general population, older people or patients with dementia or their carers and relatives 
- that the medical content should pertain to symptoms, diagnostic procedures and treatment

- that the printed material be at least three standard pages in lenght

Exclusion criteria were:

- press campaigns of initiatives or health care systems

- position papers

- statements

- newspaper articles

- materials that must be purchased

- web pages (i.e. no downloadable pdfs).

All brochures were transformed into plain text (i.e. without pictures, cartoons, bullets and text boxes). Readability was measured using the readability software Text Quest 1.9 (Paasche-Orlow et al., 2003). The following parameters were assessed for each brochure: language, source, publication year, SMOG (McLaughlin, 1969), Flesch-Kincaid reading ease index (Flesch, 1948), number of words and sentences, as well as font size (determined on a visual scale by an independent observer). To assess whether two samples of observations (brochure source: pharmaceutical vs. health advocacy groups; age: before vs. after 2005; shorter vs. longer brochures; English vs. German) came from the same distribution, the values from the variables SMOG and Flesch-Kincaid were analyzed using the non-parametric Mann-Whitney U-Test.

\section{Results}

A total of 118 brochures and other written material (e.g. booklets, guidebooks, brief information booklets, extended list of tips for caregivers) from pharmaceutical companies $(n=16)$ and health advocacy groups $(n=102)$ were analyzed. All were published between 1997 and 2007, with 25 articles in English and 93 in German. Of the 118 brochures, 31 were related to dementia in general, 72 contained medical facts about Alzheimer's disease and related memory disorders (cognitive impairment; memory loss; other dementias) and 45 covered psychosocial care or social issues (caregivers guide, health insurance, behavioral problems).

The mean SMOG readability grade was found to be $13.6 \pm 1.8$, and the mean Flesch-Kincaid was 29.4 \pm 17.2 (which corresponds to difficult texts of high-school grade (Bachmann, 2007). None of the publications had a grade level compatible with the $6^{\text {th }}$ school grade. Only 20 brochures $(17 \%)$ had a grade correlating to a school grade at or below the $12^{\text {th }}$ grade (Table 2 ). The vast majority $(n=96 ; 82 \% \%)$ of the brochures were graded to correlate above the $12^{\text {th }}$ school grade level in the SMOG formula. No difference in SMOG levels was found between brochures obtained from pharmaceutical companies and those from health advocacy initiatives $(13.2 \pm 1.4$ vs. $13.8 \pm 1.8 ; \mathrm{p}=0.11$; see also Table 2). Neither was a difference observed for brochures published prior to 
Table 2. Results of comparative analysis of readability

\begin{tabular}{|c|c|c|}
\hline \multicolumn{3}{|c|}{$\begin{array}{r}\text { OVERALL SMOG READABILITY }(\mathrm{N}=118): 13.6 \pm 1.8 \text { GRADE } \\
\text { SMOG } \leq 9^{\mathrm{TH}} \text { GRADE: }(\mathrm{n}=2) 2 \% \\
\text { SMOG } 9-12^{\mathrm{TH}} \text { GRADE: }(\mathrm{n}=20) 17 \% \\
\text { SMOG }>12^{\mathrm{TH}} \text { GRADE: }(\mathrm{n}=96) 82 \%\end{array}$} \\
\hline $\begin{array}{l}\text { Pharmaceutical source } \\
\qquad(\mathrm{n}=16): \text { SMOG } 13.2 \pm 1.4\end{array}$ & $\begin{array}{l}\text { Health advocacy groups }(n=102): \text { SMOG } \\
\quad 13.8 \pm 1.8\end{array}$ & \\
\hline $\begin{array}{l}\text { English }(\mathrm{n}=25): \text { SMOG } \\
\quad 12.6 \pm 1.5\end{array}$ & German $(n=93):$ SMOG $13.9 \pm 1.7$ & \\
\hline $\begin{array}{l}\text { Published before } 2005 \\
\quad(\mathrm{n}=58): \text { SMOG } 13.7 \pm 1.7\end{array}$ & $\begin{array}{l}\text { Published in or after } 2005(\mathrm{n}=60) \text { : SMOG } \\
13.1 \pm 2.1\end{array}$ & \\
\hline $\begin{array}{l}\text { Shorter brochures }(\mathrm{n}=59) \text { : } \\
\text { SMOG } 13.3 \pm 1.3\end{array}$ & Longer brochures $(n=59)$ : SMOG $14.1 \pm 2.1$ & $\mathrm{p}=0.01$ \\
\hline $\begin{array}{l}\text { Psychosocial care/social issues } \\
\qquad(\mathrm{n}=45) \text { SMOG } 14.0 \pm 1.7\end{array}$ & Medical facts $(\mathrm{n}=72)$ SMOG $13.3 \pm 1.9$ & $\mathrm{p}=0.04$ \\
\hline
\end{tabular}

the median publication year of 2005 compared with those published in or after 2005 (SMOG: $13.1 \pm 2.1 ; \mathrm{p}=0.75$ ). Readability was better in shorter brochures (below the median of 1436 words: SMOG $13.3 \pm 1.3$ ) than in longer ones (above median: SMOG 14.1 $\pm 2.1 ; \mathrm{p}=0.01)$. Furthermore, English brochures had a better SMOG-readability $(12.6 \pm 1.5)$ than those written in German (13.9 \pm $1.7 ; \mathrm{p}=0.001)$. Brochures with medical facts had significantly lower SMOG grades than those dealing with psychosocial care or social issues (Table 2).

The average number of words per sentence was 18. A count of more than 20 words was observed in $25.4 \%$ of all brochures. Mean font size was $11.1 \pm 1.6$. Only $23.6 \%$ of the brochures had a font size of 12 or more.

\section{Discussion}

Our analysis indicates that written patient information and educational material on dementia and related diseases require high reading skills. Previous studies have shown that the mean reading ability of patients with dementia or older people tends to be at about 6th to 8th grade levels (Davis et al., 1990; Weiss et al., 1994; Hearth-Holmes et al., 1997; Galloway et al., 2003). Therefore, the readability of the material should not exceed 8th grade (Paasche-Orlow et al., 2003). Readability tests have revealed that sentences consisting of more than 20 words are difficult to retain because of their reliance on memory and their more complex syntactic structure (Coleman, 1964; Beaman, 1984, Zakaluk and Samuels, 1988). Current EU guidelines recommend the use of brief sentences for leaflets accompanying medical products (EU, 1998). On this basis, comprehension of the material analyzed in our study will be limited.

No differences were observed in the readability of brochures produced by pharmaceutical companies compared with those obtained from other sources. 
Recently published brochures were not found to be more readable than older ones. Those that were easier to read were shorter in length and written in English rather than in German, despite a SMOG level of $12^{\text {th }}-13^{\text {th }}$ grade. Brochures that addressed psychosocial contents tended to have higher SMOG levels. Furthermore, the fonts used were often small and clearly below the size recommended for optimal readability by older recipients (12-14 point size) (Vanderplas and Vanderplas, 1980).

Some limitations of our study deserve discussion. It is possible that brochures running to fewer than three standard pages (which were excluded in the present study) are more readable. However, we are convinced that such short brochures are unlikely to contain adequate information about severe, chronic illnesses like dementia. In our experience, short brochures often just provide information about the institutions providing the product or treatment without giving any relevant content. Also, the higher SMOG levels measured in German texts compared to English texts can be explained by the fact that German is more polysyllabic than English, thus limiting direct readability comparisons between the two languages. The high SMOG readability levels (as determined by software) might be an overestimation, since the actual readability of texts might be helped by elements in the text such as diagrams and pictures, which were excluded from the texts prior to analysis. Another limitation is that the majority of texts were from German-speaking countries (mostly Germany, but also Austria and Switzerland). The remaining English brochures were from the U.K., U.S.A, Canada and Australia. It is likely that there many other printed brochures were not retrieved in our search.

The results described here are similar to those found in previous smaller studies relating to specific areas of medical interest (see Table 1). We therefore conclude that inadequate readability of written patient information appears to be a more general phenomenon in medicine. The impact, however, is likely to be more adverse for patients with dementia and cognitive decline. Such patients are often less educated and consequently more likely to misunderstand the medical information pertaining to their condition or treatment. The U.S. National Work Group on Literacy and Health and Readability Standards of Medical Schools (Paasche-Orlow et al., 2003) recommends that written material for all age groups should be at $5-10^{\text {th }}$-grade level since material at higher levels is unlikely to be understood or perhaps not even read at all. Readable patient information should be seen as a first major step in improving comprehension of medical facts. Nevertheless, other methods of communication should be implemented in order to improve patient comprehension and knowledge.

As confirmed by the present study, despite repeated scientific reports in recent years highlighting the inappropriate use of material requiring high reading skills, there seems to be no improvement in the material produced by health science professionals. Given that readability can be easily assessed by freely available software resources, we recommend careful design and prior readability testing of each informational document written for elderly people and/or cognitively impaired patients. We also conclude that, due to limitations in our study design, further studies should address the readability of printed material of fewer than 
three pages or material targeted at a younger age group such as the sons, daughters and other younger caregivers.

\section{Conflict of interest}

None.

\section{Description of authors' roles}

Mrs. Angelika Reinhold (medical student) helped in finding and collecting the brochures, calculating the reading indexes and writing the paper. Tanja RichterSchmidinger (psycho-gerontologist) participated in the design of the study and collection of the brochures. Anne-Kathrin Sulimma (medical student) evaluated the textual elements of the brochures. Harald Klein, a German expert in reading research, helped with the software. Professor Johannes Kornhuber supervised the whole project and helped with data collection. Professor Markus Weih formulated the research question, was responsible for the project and helped Mrs. Reinhold write the paper.

\section{Acknowledgment}

The authors thank Mrs. Almut Wymard for assistance in improving the language in this paper.

\section{References}

Bachmann, C. (2007). Testen Sie Ihren Text! Textanalyse. http://leichtlesbar.ch

Beaman, K. (1984). Coordination and subordination revisited: syntactic complexity in spoken and written narrative discourse. In D. Tannen (ed.), Coherence in Spoken and Written Discourse (pp. 45-80). Norwood NJ: Ablex.

Coleman, E. B. (1964). The comprehensibility of several grammatical transformations. Fournal of Applied Psychology, 48, 186-190.

Chesson, A. L., Jr., Murphy, P. W., Arnold, C. L. and Davis, T. C. (1998). Presentation and reading level of sleep brochures: are they appropriate for sleep disorder patients? Sleep, 21, 406-412.

Davis, T. C., Crouch, M. A., Wills, G., Miller, S. and Abdehou, D. M. (1990). The gap between patient reading comprehension and the readability of patient education materials. Fournal of Family Practice, 31, 533-538.

Davis, T. C., Mayeaux, E. J., Fredrickson, D., Bocchini, J. A., Jr., Jackson, R. H. and Murphy, P. W. (1994). Reading ability of parents compared with reading level of pediatric patient education materials. Pediatrics, 93, 460-468.

Estrada, C. A., Hrfyniewicz, M. M., Higgs, V. B., Collins, C. and Byrd, J. C. (2000). Anticoagulant patient information material is written at high readability levels. Stroke, 31, 2966-2970.

EU (1998). Guideline on Readability of the Label and Package Leaflet of Medical Products for Human Use. EU Guideline 92/27/EEC Council Directive. Brussels: European Commission. 
Flesch, R. (1948). A new readability yardstick. Fournal of Applied Psychology, 32, 221-233.

Galloway, G., Murphy, P., Chesson, A. L. and Martinez, K. (2003). MDA and AAEM informational brochures: can patients read them? Fournal of the American Association of Neuroscience Nurses, 35, 171-174.

Gunning, R. (1952). The Technique of Clear Writing. New York: McGraw-Hill.

Hearth-Holmes, M. et al. (1997). Literacy in patients with a chronic disease: systemic lupus erythematosus and the reading level of patient education materials. Fournal of Rheumatology, 24, 2335-2339.

Klein, H. (2004). TextQuest Version 1.9: German Handbook for Text Analysis.

Kubba, H. (2000). Reading skills of otolaryngology outpatients: implications for information provision. Fournal of Laryngology and Otology, 114, 694-696.

Mader, T. J. and Playe, S. J. (1997). Emergency medicine research consent form readability assessment. Annals of Emergency Medicine, 29, 534-539.

McLaughlin, G. (1969). SMOG grading: a new readability formula. Fournal of Reading, 12, 639-646.

National Literacy Trust (2008). http://www.literacytrust.org.uk/campaign/SMOG.html

Paasche-Orlow, M. K., Taylor, H. A. and Brancati, F. L. (2003). Readability standards for informed-consent forms as compared with actual readability. New England fournal of Medicine, 348, 721-726.

Powers, R. D. (1988). Emergency department patient literacy and the readability of patient-directed materials. Annals of Emergency Medicine, 17, 124-126.

Smith, H., Gooding, S., Brown, R. and Frew, A. (1998). Evaluation of readability and accuracy of information leaflets in general practice for patients with asthma. BMF, 317, $264-265$.

Vanderplas, J. V. and Vanderplas, J. H. (1980). Some factors affecting legibility of printed materials for older adults. Perceptual and Motor Skills, 50, 923-932.

Weiss, B. D. and Palmer, R. (2004). Relationship between health care costs and very low literacy skills in a medically needy and indigent Medicaid population. Fournal of the American Board of Family Practice, 17, 44-47.

Weiss, B. D., Hart, G. and Pust, R. E. (1991). The relationship between literacy and health. fournal of Health Care for the Poor and Underserved, 1, 351-363.

Weiss, B. D. et al. (1994). Illiteracy among Medicaid recipients and its relationship to health care costs. Fournal of Health Care for the Poor and Underserved, 5, 99-111.

Zakaluk, B. L. and Samuels, S. J. (1988). Readability: Its Past, Present and Future. Newark, NJ: International Reading Association. 